\title{
What is new with Artificial Intelligence? Human-agent interactions through the lens of social agency
}

\author{
Marine Pagliari $^{1,2}$, Valérian Chambon ${ }^{1^{*}}$, Bruno Berberian ${ }^{2^{*}}$ \\ ${ }^{1}$ Institut Jean Nicod, Département d’Études Cognitives, École Normale Supérieure, \\ CNRS, PSL University, Paris, France. \\ ${ }^{2}$ Information Processing and Systems, ONERA, Salon de Provence, Base Aérienne 701, \\ France
}

*shared senior authorship

Corresponding authors: Marine Pagliari (marine.pagliari@gmail.com); Institut Jean Nicod, UMR 8129, Pavillon Jardin, École Normale Supérieure, 29, rue d’Ulm, F-75230 Paris cedex 05. Bruno Berberian (bruno.berberian@onera.fr); Valerian Chambon (valerian.chambon@gmail.com). 


\section{Abstract}

The introduction of automated systems, and more broadly of Artificial Intelligence (AI), into many domains has profoundly changed the nature of human activity, as well as the subjective experience that agents have of their own actions and their consequences - an experience that is commonly referred to as "sense of agency" (SoA). In this review, we propose to examine the empirical evidence supporting this impact of automation on individuals' sense of agency, and hence on measures as diverse as operator performance, system explicability and acceptability. Because of some of its key characteristics, AI occupies a special status in the artificial systems landscape. We suggest that this status prompts us to reconsider human-AI interactions in the light of human-human relations. We therefore approach the study of joint actions in human social interactions to deduce what are the key features necessary to develop a reliable SoA in a social context. We suggest that the study of social interactions and the development of SoA in joint actions can help determine the content of relevant explanations to be implemented in AI to make it "explainable". Finally, we propose possible directions to improve human-AI interactions and, in particular, to restore the SoA of human operators, improve their confidence in the decisions made by artificial agents, and increase the acceptability of such agents.

Keywords: sense of agency; social agency; joint action; EXplainable Artificial Intelligence; acceptability; human-AI interaction 


\section{Introduction}

Over the past few decades, automation has profoundly changed our daily lives, and predictions for the future indicate that this trend will continue to grow, especially with the advent of Artificial Intelligence (AI). The introduction of automation into our lives has many benefits, including increased safety for humans. However, the interposition of automated systems between human operators and control processes has radically changed the nature of human activity, from direct manual control to partial or full supervision. While the negative impact of such a change on operators' performance has been widely documented, the cognitive mechanisms involved in this degradation are still poorly understood.

Recently, the sense of agency (i.e., the feeling of being in control of our actions and their consequences on the environment) has been presented as a potential mediator of this degraded state of performance. Indeed, interaction with an automated system can alter the experience of control over our actions and create ambiguous situations as to who has control. The detrimental effect of automation on agency has been documented in a large number of studies. From an operational point of view, loss of agency in human-machine interactions leads not only to a decrease in the acceptability of automated systems, but can also lead to a disengagement of the operator from the task at hand. The continuing evolution of automated systems, and in particular the advent of AI, is likely to further alter the relationship between agency and technology. In this review, we propose to investigate the nature of this relatively

recent change in human technological history and its potential impact on the agentive experience of human operators. 
To do so, we will first examine whether, and to what extent, some of the negative consequences of using technology can be explained by a disruption in the development of our sense of control. We will discuss how the experience of control develops when we act alone or in interaction with automated systems, and then highlight the singularity of Artificial Intelligence compared to automated systems in general, and the new questions it raises in terms of interaction with human operators. We will examine some key features of AI that contribute to changing the role of the technological tool in human decision-making processes and their impact on the sense of agency. We will see how these changes invite to consider human-AI interactions in the light of human-human relations. We will then turn to studies of joint action in social interactions in an attempt to deduce the characteristics that enable the development of a sense of agency in social contexts. Finally, we will propose to transfer insights gained from our study of human social agency to the field of eXplainable Artificial Intelligence (XAI). This research area aims at making AI more readable and transparent to humans by producing explanations of how AI makes decisions. We suggest that studying social interactions and understanding the development of a sense of agency in human joint actions can help refine the content of explanations to be implemented in AI to improve human-AI interactions. Giving access to the different levels of intention (proximal and distal) implemented by AI could help restore human operators' sense of agency, improve their confidence in the decisions made by artificial agents, and ultimately increase acceptability towards such agents. 


\section{Sense of Agency and technology}

\subsection{Impact of automation on human operators}

Over the past few decades, automation technology has become a pervasive phenomenon and has profoundly changed our daily lives. Automation refers to the process of partially or completely handling over a task usually performed by a human to a machine or system (Sheridan, 2002). The initial reason for the introduction of automation was to reduce the workload of operators, and thus reduce operational costs and errors, while increasing accuracy (Sarter et al., 1997). In aviation, the introduction of automated technologies, such as systems that provide vital automated aids, has significantly improved current levels of safety (International Civil Aviation Organization, 2017).

The complexity and ingenuity that characterize automated systems tend to focus public attention on the technical capabilities of automation. However, while the introduction of automation into a system can be viewed as a simple substitution of a machine activity for a human activity (Woods \& Tinapple, 1999), human activities are impacted often unintentionally and unanticipated by automation designers. As a matter of fact, the interposition of automated systems between human operators and control processes has radically changed the nature of human activity from direct manual control to partial or total supervision (Dekker \& Woods, 2002). This change is far from trivial and creates new burdens and complexities for individuals and teams of practitioners charged with operating, troubleshooting, and managing automated systems. 
The negative impact of such a change on operators activities is widely documented through the notion of out-of-the-loop performance problem, i.e., OOTL, (Endsley \& Kiris, 1995; Kaber \& Endsley, 1997). An out-of-the-control-loop operator has difficulty detecting errors or failures in the system (Ephrath \& Young, 1981; Kessel \& Wickens, 1982), understanding its current state (Christoffersen \& Woods, 2002; Sarter et al., 1997; Sarter \& Woods, 1995), and determining appropriate actions for the next task (Endsley, 1999). Decreased vigilance, complacency or overconfidence in the system's capabilities, and a loss of situational awareness on the part of the operator have been identified as factors that may contribute to this phenomenon. For decades, the problem of OOTL performance has been a major concern in the human factor literature. However, the cognitive mechanisms involved in the OOTL phenomenon are still poorly understood.

Recently, the notion of agency has been presented as a potential mediator of this degraded state of performance (Berberian, 2019). The term 'sense of agency', or sense of control, refers to the subjective awareness of initiating, executing, and controlling one's own volitional actions in the world (Jeannerod, 2003). This form of self-awareness is important not only for motor control but also for social interactions, the ascription of causal responsibility, and serves as a key motivational force for human behavior.

Early studies in the aerospace field sought to understand how automation in aviation affects the sense of agency. Automation was first shown to reduce pilots' sense of control (Norman et al., 1990). More recently, Berberian et al. (2012) explored the modulation of the sense of agency through automation in a task implementing different degrees of autopilot assistance in a flight simulator. In this study, subjective reports of sense of agency were asked 
of participants to measure the degree to which they felt they had caused the maneuver to avoid the conflict, ranging from no causal involvement to high causal involvement. The results showed that participants' sense of agency decreased with the level of automation involved (Berberian et al., 2012). This alteration of the agentive experience has since been highlighted in various works (Grynszpan et al., 2019; Sahaï et al., 2019; Yun et al., 2018; Zanatto et al., 2021). In contrast, other research suggests a positive influence of automation on the sense of agency (Vantrepotte et al., 2021; Wen et al., 2015a, 2021). As an illustration, Wen and colleagues (Wen et al., 2015a) designed a computer assistance program in a dotmoving game, in which the computer only ignored participants' incorrect commands. The results showed that when there is a response delay in the game, making the task very difficult, the computer assistance significantly increased participants' sense of agency compared to the condition where all participants' commands were executed.

Taken together, these results show that advances in automation technologies can modulate the development of the experience of agency. This modulation of our experience of agency can have dramatic operational consequences along a number of key dimensions:

- Experience of agency and acceptability: Decrease in the sense of control when interacting with highly automated systems is likely to seriously threaten the acceptability of the system's decisions by human operators. To be acceptable, a new technology must be reliable, efficient and useful. However, these qualities do not guarantee acceptability to the human operator. Indeed, users strongly desire to feel that "they are in charge of the system" and that the system "responds to their actions" (Shneiderman \& Plaisant, 2004). This link between agency and acceptability was highlighted in a recent study showing that 
a diminished sense of agency in human-system interaction affects system acceptability (Le Goff et al., 2018).

- Experience of agency and operator involvement in the task: Any change in self-agency can modulate the operator's involvement in the task at hand. In particular, human-machine interface research has shown that driving support effectively decreases driver control activity (Mulder et al., 2012) and that this decrease is linked to driver disengagement (Navarro et al., 2016). As an illustration, a recent study showed that even when vehicle supervision successfully reminded drivers to hold the wheel and look at the road, people still did not engage in driving and were unable to prevent the vehicle from crashing into a conflicting object (Victor et al., 2018). Yet, it is know that a reliable sense of agency is essential for the attribution of causal, but also moral and legal, responsibility (Bigenwald \& Chambon, 2019). Furthermore, a relationship between sense of control, motivation, and willingness to exert effort has been demonstrated (Eitam et al., 2013; Wang et al., 2019). A loss of agency could therefore constitute a form of moral disengagement from our actions that would disturb the mechanism classically used to regulate human behavior (Bandura, 1999). This disengagement can be problematic when operator decision-making is required (Wen et al., 2019) and leads to difficulties when the operator must regain manual control (Navarro et al., 2016). Notably, a previous study on emergency braking when using cruise control found that reaction time for braking was significantly longer when people used cruise control rather than manually controlling vehicle speed (Jammes et al., 2017). 
- Experience of agency and operational performance: A change in the feeling of agency could have a direct influence on cognition, and through this, on operational performance. In particular, significant consequences in terms of attention and memory have been demonstrated. Thus, experimental work suggests that the sense of agency strongly influences attention allocation such that people effectively monitor events that are relevant to themselves (i.e., under their control), but do not pay much attention to events that are outside of their control (Wen \& Haggard, 2018). Furthermore, studies investigating errorrelated potentials (i.e., brain activity associated with monitoring of the consequences of an action, e.g., San Martín (2012), for a review) show a degradation of monitoring associated with a reduced sense of agency (Bednark \& Franz, 2014; Caspar et al., 2016; Kühn et al., 2011; Li et al., 2011; Timm et al., 2014). Finally, Hon and Yeo (2021) report evidence that stimuli for which one feels a sense of agency are, in fact, remembered better than their counterparts without such a sense (Hon \& Yeo, 2021).

Thus, sense of agency may play an important role in the OOTL phenomenon, as well as in the level of acceptability of automated systems and the performance of the human operator. With the next generations of highly automated systems, a major challenge for the HCI community will consist in clarifying this relationship between automation and sense of agency. A better understanding of this interaction can provide a useful framework for thinking about interactions with automated technology and, in particular, for optimizing humanautomation interactions. 


\subsection{Sense of Agency: what is it, and how does it develop?}

As mentioned above, the sense of agency is traditionally defined as the experience of controlling one's actions, and, through them, events in the external world (Haggard \& Chambon, 2012). A functional sense of agency allows individuals to distinguish events that they have caused from those for which they are not responsible, but which, for example, were caused by chance of by other agents. As such, a sense of agency is considered a cornerstone of human experience (Haggard, 2017; van Hateren, 2015) and a deficient sense of agency is associated with various disabling clinical conditions, such as depression (Haggard \& Chambon, 2012) or schizophrenia (Garbarini et al., 2016; Voss et al., 2010). In today's society - in which one's actions can have consequences for the lives of others -, causal attribution of behavior is essential. In particular, self-agency plays a central role in society as the basis for legal responsibility or fair retribution for the work done (Haggard, 2017; Hallett, 2018).

It has been proposed that the sense of agency is composed of various subcomponents such as sense of intentionality, sense of initiation, and sense of control (Pacherie, 2007). In this review, we will approach the notion of sense of agency primarily from the perspective of sense of control. Indeed, insofar as we place ourselves in an interaction where a system makes decisions, the sense of initiation of the action - and, to a lesser extent, the sense of intentionality - is most often automatically attributed to the system. Our objective will not be to question the conditions of emergence of an "artificial" sense of intentionality or action initiation, but to examine the conditions necessary for the human operator to develop a feeling of control over the effects of an action taken by an automated system. 


\section{Sense of agency develops along the intention-action-effect chain}

Normal human experience consists of a coherent flow of sensorimotor events, in which we first formulate action intentions and then move our bodies to produce a desired effect (Haggard et al., 2002). This involves linking our intentions to our actions, and our actions to their effects - i.e. the internal states they change or the events they produce in the external world. The chain "intention-action-effect" is thus key to developing a reliable sense of agency (Chambon \& Haggard, 2013; Sidarus \& Haggard, 2016). In particular, two dimensions of agentive experience have been highlighted: one prospective, the other retrospective.

Many studies have focused on the role of monitoring the consequences of our actions, i.e. on the retrospective dimension of sense of agency. Within this framework, it has been repeatedly shown that a sense of agency arises when external events following our action are consistent with predictions of action effects made by the motor system while we are performing or simply intending to perform an action (Chambon, Sidarus, and Haggard 2014, for a review). It is also recognized that the neurocognitive mechanisms involved in the sense of agency rely on a variety of cues, i.e. internal cues such as motor signals or sensory feedback, and external cues such as situational cues or context (Moore \& Fletcher, 2011). These cues help verify the integrity of the "intention-action-effect" causal chain, once the action is performed and its effects are known (that is, retrospectively). The brain's agency system thus functions as a central processing system that brings together internal and external cues used in combination to establish the most robust agency representation (Moore et al., 2009). Multiple cues contribute to the sense of agency and cue integration approaches have 
been shown to be effective in modelling both human perception and action experience (Moore \& Fletcher, 2011).

Another key dimension of agency has been emphasized more recently: the prospective dimension, which focuses on the intention-action link in the "intention-action-effect" chain mentioned above. This dimension of agentive experience concerns the processes that take place prior to action, and thus prior to receiving information about the actual effect of the action (Chambon \& Haggard, 2012; Wenke et al., 2010). According to the prospective view of the sense of agency, the ease (or difficulty) with which an action is prepared, or selected from several possible actions, could also boost (or reduce) the sense of agency. This suggests that the sense of agency does not only depend on retrospective signals comparing predicted and actual sensory feedback, but also emerges from internal circuits related to action preparation and selection. In other words, the sense of agency could also rely on an early signal generated while we prepare or select the appropriate action to take.

Importantly, the sense of agency has been shown to be a flexible mechanism that can be modulated under certain conditions. In the next section, we examine different modulators of the sense of agency and discuss how automation of all or part of the intention-action-effect causal chain is likely to interact with them.

\section{Degree of involvement and level of automation}

It has been shown that user involvement in a task is critical for their perceived control. Indeed, a greater involvement of the user in an action increases the perceived control of this action (Baronas \& Louis, 1988). Engagement in a task can be modulated by varying the 
intentionality of the action itself. For example, Caspar et al. (2018) showed a reduced sense of agency in agents receiving coercive instructions to perform an action compared to situations where they freely chose the action to perform. They also found a reduced sense of agency in commanders who coerced agents to perform an action compared to situations where they acted on their own. Ordering someone to do something thus decreases the individual sense of agency for that action and thus inevitably reduces the sense of responsibility for that action (Caspar et al., 2018). This link between sense of agency and freedom of action choice was also highlighted by Barlas \& Obhi (2013) in an experiment varying the number of alternatives. They recorded a stronger sense of agency among participants when the number of alternatives was maximal, an intermediate sense of agency when participants had a medium level of action choices, and a weaker sense of agency when they had only one choice available to them. This result suggests that reduced opportunities for voluntary action selection, and thus indirectly a lower degree of investment in action, decreases the sense of agency.

In human-machine interactions, the degree of involvement in the task varies according to the degree of automation implemented. A number of studies suggest that increasing the level of automation proportionally decreases the development of the operator's sense of control. For example, Berberian and colleagues (2012) studied participants' sense of agency while performing an aircraft supervision task using a flight simulator under different levels of automation. The task required the participant to observe a flight plan and after a random time interval, a conflict occurred due to the presence of another aircraft. The participant then had to decide on an appropriate command and execute it using a button interface. Following an established classification (Sheridan \& Verplank, 1978), the task included different levels of 
automation, from the user having full control (no automation) to the computer performing the entire task with the participant merely observing (full automation). The authors found a decrease in self-agency concomitant with increasing level of automation, and argued that the increasing level of automation tended to distract operators from the results of their action, decreasing their sense of control and thus disrupting their overall performance.

In a similar vein, Yun et al. (2018) measured drivers' sense of agency during assisted and automated driving in a driving simulator. Their results showed that in the assisted driving condition, the sense of agency was significantly lower than in the manual driving condition (Yun et al., 2018). In addition, Mulder et al. (2012) showed that driving assistance effectively decreased driver control activity (Mulder et al., 2012) and was related to driver disengagement (Navarro et al., 2016). However, Ueda et al. (2021) more recently showed that human operators' sense of agency could be enhanced by increasing automation, but began to decline when the level of automation exceeded $90 \%$. The author therefore suggested that allowing operators to contribute slightly to monitoring the ongoing operation of an automated tool could be an efficient solution for maintaining their sense of agency while producing maximum performance improvement (Ueda et al., 2021).

Together, these results suggest that it is not the level of automation itself that modulates the sense of control in the first place, but rather the amount of control remaining over the action. One possible hypothesis to explain this decrease in the sense of agency when interacting with automated systems is that the amount of control remaining is inversely proportional to the level of assistance (Berberian et al. 2012). On the one hand, in situations where automation only provides assistance and actions are still performed by a human agent, 
that agent's decision is only "mediated" by the technology and the agent's sense of agency is not or minimally altered. On the other hand, in situations where automation is predominant (e.g., a supervisory task), the agent's decision has less weight or is even useless, preventing the agent from developing control over the action performed. In this case, the development of a sense of agency is hindered by the high degree of automation.

\section{Time course of voluntary actions and latency effects}

The time course of the intention-action-effect chain is a key variable in the development of a sense of agency in human agents. Thus, increasing the interval between action and effect (i.e. delay) is a procedure often used to weaken the sense of agency in laboratory experiments. This manipulation of the sense of agency is derived from a classic self-touch delay paradigm, although the original study did not directly examine the sense of agency. Blakemore and colleagues (Blakemore et al., 1999) have shown experimentally that increasing the delay between a self-produced action and the resulting tactile stimulus decreases the attribution of the action to the self (Blakemore et al., 1999). It has been argued that increasing the delay increases the intensity of the sensation because the stimulus no longer matches (in time) the motor command. Since then, many studies have shown a gradual decrease in the sense of agency as delay increases (Ebert \& Wegner, 2010; Farrer et al., 2013; Hon et al., 2013; Kawabe, 2013; Kühn et al., 2011; Sato \& Yasuda, 2005; Wen, 2019).

While most studies have focused on the impact of the delay between action and its consequences, some studies have also highlighted the role of the delay between intention and action on the feeling of agency. This is particularly true of Wegner's work on the priority 
principle (Wegner \& Wheatley, 1999). The priority principle requires that the perceived causes that precede an action be temporally closely related to the consequences of that action. The intention to act must have been formed just before the action is performed. In other words, for an agent to feel control over an action, the intention that initiates that action must occur within a sufficiently short period of time before the actual execution of the action (Hindriks et al., 2011).

Interestingly, the temporality of action is also considered a major issue in the field of ergonomics. Better known as latency - the time that elapses between the moment a device is physically moved and the moment the corresponding update appears on the screen (Foxlin, 2002) -, the delay between action and its consequences is a critical factor for the quality of Human-Computer Interaction (HCI) and a major bottleneck for usability (MacKenzie \& Ware, 1993). Although a number of studies have shown that, in HCI situations, a longer interval between action and effect is associated with a lower sense of agency (Berberian et al., 2013; Wen et al., 2015b), delay influences the measures of agency via multiple possible processes, such as graded response, task performance, sensory pre-activation, and temporal perceptual sensitivity (see Wen (2019) for a review). The presence of a delay between the action and its consequence remains, however, essential to account for alterations of the agentive experience due to the increased latencies introduced by automation in the intentionaction-effect chain.

Finally, while time is an essential component in the development of a sense of agency, it can be noted that being the intentional agent of an action can also modulate our temporal perception of the events surrounding our actions. Specifically, in the case of a voluntary (vs. 
involuntary) action, the perceived onset of the action is shifted towards the perceived onset of its consequence, and vice versa, resulting in a "compression" of the perceived temporal delay between the action and its outcome (Di Costa et al., 2018; Haggard et al., 2002). This subjective compression is referred to as the "intentional binding" phenomenon (Haggard et al., 2002). In addition to explicit (self-reported) measures (Barlas \& Kopp, 2018; Sidarus et al., 2017; Wenke et al., 2010), intentional binding is now extensively used as an implicit measure of the sense of agency (see Moore \& Obhi, 2012 for a review).

\section{Performance levels and automation}

Metcalfe and Greene (2007) were the first to show that agency judgments are strongly correlated with performance on a task, even when participants know that their performance is largely due to external factors (Metcalfe \& Greene, 2007). More recently, Van der Wel et al. (2012) also showed a significant negative correlation between participants' error scores and their agency ratings. These results highlight another component of Wegner's theory of apparent mental causation (Wegner \& Wheatley, 1999): the consistency principle. As participants perform better on the task, their performance expectations likely become more consistent with actual performance, resulting in a greater sense of control (van der Wel et al., 2012).

This relationship between performance and agency experience is also present in our interactions with machines. Wen et al. (2015a) first showed that level of performance produced by an action might be more important than action-outcome association in modulating the operator's sense of agency. Indeed, if automation removes some control from 
users, it also provides more reliable and secure control over outcomes. The authors observed that participants' sense of agency increased with better performance in an assisted condition compared to a self-control condition, even though a large portion of their commands were not executed (Wen et al., 2015a). In a goal-directed motor task in which computer assistance ignored erroneous user commands, Wen et al. (2015c) also showed that both sense of agency and performance could be improved by automation. In this task, computer assistance thus significantly improved performance and sense of agency compared to the condition in which all user commands were executed (Endo et al., 2020; Wen et al., 2015c).

Consistent with these results, Tanimoto et al. (2017) showed that a semi-automatic system that combined an ideal work trajectory with the operator's manual trajectory maintained the operator's sense of agency at a high level, similar to that of manual control, while improving performance at the same time (Tanimoto et al., 2017). More importantly, Tanimoto et al. (2017) also found that the sense of agency was strongly weakened if the semi-automatic system performed goal-directed assistance (providing a distal outcome) rather than trajectory assistance (providing a proximal outcome). This result is consistent with findings from experimental psychology that both proximal and distal action outcomes are important for developing a reliable sense of agency (Metcalfe et al., 2013; Vinding et al., 2013).

In summary, a system that improves the performance of a human operator also increases the operator's sense of control. More interestingly, studies show that the operator's sense of control is enhanced even in situations where improving performance involves ignoring some of the operator's behavior - and thus ultimately reducing the actual control the operator has over the action. 


\section{Action-choice facilitation and readability of automated system choices}

Experimental studies have shown that predictability influences the sense of agency. By manipulating the congruence between subliminal primes and the selection of a motor response on a keyboard, Wenke, Fleming \& Haggard (2010) showed that compatible primes did not facilitated responding by speeding up response times, but were associated with a higher sense of control (Wenke et al., 2010). Chambon and Haggard (2012) suggested that this priming effect was independent of motor execution itself but stemmed from the ease of action selection induced by the prime-target compatibility (Chambon and Haggard 2012; see also Chambon et al. 2013; Chambon, Moore, and Haggard 2015). Building on this work on action selection and self-agency, Sidarus, Chambon and Haggard (2013) designed a task in which both the facilitation of action selection (compatible or incompatible primes) and the probability of occurrence of an effect, were varied. Importantly, they showed that an expected effect led to a higher evaluation of the feeling of control than an unexpected effect. More interestingly, they observed an interaction effect between the facilitation of action selection and the probability of effect occurrence: when an action was followed by an expected effect, there was no difference in the evaluation of control whether the prime was congruent or incongruent. However, when the action produced an unexpected effect, congruent primes (i.e. action facilitation) resulted in a higher sense of control than incongruent ones (Sidarus et al., 2013).

While the ability to predict the outcome of our actions is central to the development of reliable experience of agency, it is also clear that advances in automation technology tend to develop automatic cascades and reaction chains that reduce or even eliminate predictability 
and result in unexpected events. Such opacity makes it difficult for the operator to relate the system intention to actual state and predict the sequence of events that will occur. This lack of transparency on how the system makes decisions, or simply operates, is considered a key factor in understanding the impact of automation on the operator's sense of agency. The link between transparency of system intentions and the operator's sense of control was highlighted in a recent study (Le Goff et al., 2018). Specifically, this study showed that providing informational messages containing a system's intentions during a supervision task improved the acceptability of the automated system and the sense of control of the user supervising the system (Le Goff et al., 2018). Thus, displaying system intentions before an action is a good candidate for maximizing the experience of agency in supervision tasks, and for increasing system acceptability as well.

Taking together, these different results confirm that (1) the sense of agency is a flexible mechanism that can be modulated by multiple variables and (2) our interactions with technology can significantly alter the agentive experience. While these issues (i.e., level of automation, change in performance, latency, system opacity) are now relatively well documented, the evolution of technological systems generates new challenges for the human operator experience, which are directly related to the nature of our relationship with technology. Indeed, in all the examples we have mentioned, technology is perceived as a mere tool at the disposal of the human operator, rather than a full-fledged member of the interaction. With the advent of Artificial Intelligence and the increasing autonomy of technological systems that accompanies it, artificial agent should no longer be seen only as 
servants but as teammates (McNeese et al., 2018). This development generates new interaction problems that may revive interest in the role of social context on the experience of control. Interestingly, several recent studies have shown that the presence of an interaction partner can alter the sense of agency. The following section aims to highlight the changes brought about by the advent of AI as a "partner" (rather than just a tool) in our relationship to artificial agents, and the potential impact of these changes on human agency.

\section{What is new with AI?}

Artificial Intelligence (AI) emerged in the 1950s and included in its initial definition elements related to learning, memory organization and reasoning (McCarthy et al., 1955). AI is now defined as a sub-discipline of computer science that aims to produce programs that simulate human intelligence (American Psychological Association, 2020), i.e. to create systems capable of performing tasks that normally require human intelligence. It is now commonplace to say that Artificial Intelligence is becoming increasingly pervasive in our daily lives. Many of our actions are indeed mediated by decisions taken by AI and its use tends to be democratized in various fields such as transportation, security, medicine, finance, defense, etc. While the use of AI today may seem trivial, its use involves life-changing decisions for some people. AI technologies are in fact likely to make increasingly important decision in the coming decades, and it is therefore critical for ethical issues to consider the responsibility of actions arising from AI decisions. These actions still require the approval or at least the supervision of human operators, which raises the question of the new type of interaction with human operators that AI promotes. 
The following sections aim at highlighting the singularity of Artificial Intelligence compared to automated systems in general, and the new questions it raises for humanmachine interactions.

\subsection{AI: a new type of interaction with human agents}

To better understand why the introduction of AI has initiated a new type of interaction with human agents, it is essential to revisit the difference between intelligent systems (such as Artificial Intelligence) and automated systems. Bigenwald (2018) proposed a useful taxonomy to better capture the legal status of Artificial Intelligence. This taxonomy defines 3 broad classes of artificial systems with their specific properties. First, automated systems are complex rule-based systems. Second, autonomous systems are systems capable of a certain degree of adaptability, learning and evolution, and are generally capable of goal-oriented behavior. Finally, intelligent systems are systems capable of performing human cognitive tasks, and for which the issue of opacity or the "black box" is problematic - i.e. some of the "reasoning" produced by intelligent programs is untraceable and/or confusing to the human mind (Bigenwald, 2018). If these distinctions and issues are considered at the legal level, they must also be considered when thinking about the interactions these systems are likely to have with human agents at the cognitive level.

Let us first note that the notion of determinism plays an important role in the differences between automation and AI. We mentioned that automated systems are capable of doing things automatically, but always following explicit decision rules. For these systems, the 
decision rules are clearly established and accessible, i.e. they are bound with explicit programming and rules, through which the information given as input to the system will produce a predictable - deterministic - output. In contrast, AI has the ability to use data to create not only its own ontologies, but also its own decision rules. Importantly, huge amounts of data are now available to AI equipped with new tools to process and make sense of it neural networks, graphs or deep machine learning algorithms. As such, AI is not deterministic in that its decision rules are derived from the set of data used to train the system itself, and hence the system's decisions will always involve a small amount of uncertainty - just as in the case of the human brain (Shekhar, 2019). Establishing its own decision rules has advantages for AI that have led to its widespread adoption. In particular, AI algorithms often perform better than deterministic algorithms that encounter problems of generalizability, adaptation to new contexts or learning transfer (Botvinick et al., 2019). This performance allows AI to be used in increasingly complex environments and situations. However, a consequence of this is that the inner workings of the $\mathrm{AI}$ and its decision-making processes very often remain inaccessible, if not difficult to represent in intelligible symbols. This is what is referred to as the opacity, or the "black box", of AI.

In summary, AI systems are characterized by their non-deterministic, complex behavior and their autonomy. These characteristics translate into an increasing opacity of these systems for the human operator. At the same time, the increasing autonomy of artificial agents gives them a completely different role from the one initially assigned to the machine, so that artificial agents can now be considered as full crew members. This results in the introduction of new coordination requirements and the emergence of new categories of problems due to failures in the human-AI relationship. It is therefore essential to consider the potential impact 
of the artificial agent, understood as a teammate, on the control experience. As such, studies on the development of agency during joint actions in a social context could shed new light on how human-AI interactions modify the sense of agency of human operators.

\subsection{From mediated-agency to social agency}

\subsubsection{Role of the social context on the sense of agency}

In the last decade, the impact of a social context on the individual's sense of agency - i.e. how sense of agency develops in our interactions with others - has gained considerable traction (Brandi et al., (2019) for a review). An important finding is that the social context can diminish, or hinder, agentive experience. This finding has been popularized through the notion of "diffusion of responsibility" - the idea that the presence of others modifies the individual's behavior by making them feel less responsible for the consequences of their actions (Bandura et al., 1996). Similarly, acting under coercion has recently been shown to alter the subjective experience of being the author of an action. Thus, Caspar et al. (2016) showed that the neural processing of the outcome of an action performed under coercion was more similar to that observed during a passive movement than during an intentional action (Caspar et al., 2016). In addition, the presence of others would lead agents to feel less responsible for the outcome of group decisions, especially those with negative consequences (Forsyth et al., 2002; Mynatt \& Sherman, 1975). The presence of others also reduces agency by increasing the ambiguity of authorship, i.e. by weakening the neural linkage between one's actions and their outcomes (Beyer et al., 2017). Finally, the presence of another individual 
(Beyer et al., 2017) or a robot (Ciardo et al., 2018) has been shown to decrease the sense of agency over external events, even when people actually have full control. In short, under ordinary circumstances, the sense of agency is generally lower when people share control with robots, compared to the condition in which people perform actions alone. It should be noted that the opposite effect has also been demonstrated in the experimental literature. Wegner et al. (2004) first demonstrated that the existence of a "vicarious" agency in a social context. In a seminal experiment, they showed that the sense of agency was increased when participants heard some instructions for an action, even if the action was performed by another person hidden from their view. This result is one of the first to suggest that we can develop a sense of agency for an action performed by a third party (Wegner et al., 2004).

If the presence of other people (human or artificial) modulates individuals' sense of agency, our interactions with others also have a significant role in how our experience of control develops. Some daily tasks involve coordinating our efforts with others to achieve a common goal: "joint action" has been defined as any form of social interaction whereby two or more individuals coordinate their actions in space and time to bring about a change in the environment (Sebanz et al., 2006). In other words, joint action refers to the interdependent interactions involving two (or more) co-agents whose actions are directed toward a common goal (Sahai et al., 2017).

A series of behavioral experiments has first shown that knowledge about a co-actor's task affects the planning and performance of one's own action, even when the other's role need not to be considered (Atmaca et al., 2008; Sebanz et al., 2003, 2005). The results suggest that participants anticipate the other's action, which increases their own tendency to act. 
Relatedly, Obhi \& Hall (2011) showed that sense of agency could be enhanced by the actions of another person in a joint action task in which participants acted one after another. The results showed that both participants experienced a comparable sense of agency on the outcome produced. These findings support the idea that interaction partners process the causal link between each other's actions and the sensory outcomes of those actions, which led the authors to support a "we-agency" hypothesis (Obhi \& Hall, 2011). The existence of a "wemode" in social interaction has been proposed to explain this modulation of the agentive experience in social context (Gallotti \& Frith, 2013). Specifically, the "we-mode" is a mode during which people automatically track their co-actors' attention (Böckler et al., 2012; Samson et al., 2010), their performance (Sebanz et al., 2005), and their beliefs (Apperly \& Butterfill, 2009; Kovács et al., 2010).

Recently, Silver and colleagues (2020) have developed a theoretical framework that captures the different faces that the sense of agency can take in a social context. Specifically, the authors suggest that the wide variety of agentive experiences can be represented along a continuum, with cooperation as the primary dimension. In this continuum, the presence of cooperative elements within an interaction should enhance agency, whereas a social interaction with little or no cooperation should decrease agency. Because there is a great variety of possible responses from one agent to another, social contexts lead to highly unpredictable responses due to the reduced ability to make predictions about the other's behavior. Silver et al.'s agentive continuum is as follows: the most embedded type of joint agency is the "we-agency". In this particular instantiation of joint agency, the co-actors share a common agentive identity and a common goal, but the boundaries between self and other are also blurred. Note that here this blurring of the self is experienced positively (Wahn et al., 
2018). Second, in interactions where the self/other distinction is intact (no ambiguity about the origin of the action), but where the agents are engaged in joint action, shared agency is induced: self-agency and joint agency coexist. Vicarious agency occurs when the result of another agent's action is wrongly attributed to the self, while violated agency occurs when the result of our own action is wrongly attributed to another agent who did not directly cause the action. Finally, interfered agency occurs when goals are ill-defined, or when there is no cooperation, or when the actions of the other agent are unpredictable. In this case, the presence of another agent interferes with our own agency.

\subsubsection{The construction of the "we-agency"}

A critical question is that of the mechanisms underlying the emergence of this "we-agency" in joint actions. It has been proposed that the sense of agency in joint actions relies on the same principle of congruence between predicted and actual outcomes as that involved in individual actions (Pacherie, 2012). As previously mentioned, individual sense of agency develops along the intention-action-effect chain. Along this chain, the strength of an individual's sense of agency for an action depends on how accurately their predictions about the consequences of their action (at the cognitive, perceptual, and sensorimotor levels) match its actual consequences.

While the same congruence principle likely applies to joint actions, prediction becomes a much more complex task in joint actions (Pacherie, 2014). Indeed, in joint actions, agents must not only predict the consequences of their own actions, but they must also make predictions for the actions of their coagents, and integrate the prediction of self and others to 
construct predictions about the co-action (Pacherie, 2012). Predictability of others' actions has been shown to modulate joint agency (Bolt \& Loehr, 2017). A higher sense of shared control was evidenced with a more predictable co-agent, showing that people rely on predictions of others' actions to derive a sense of "we-agency" during interpersonal coordination. However, in joint actions, agents do not have direct access to the co-agent's intentions, motor commands, or sensory feedback, making it impossible to accurately match sensory feedback to the co-agent's action. In tasks involving joint actions, the attribution of control is usually vague as a result.

How does the prediction mechanism operate in joint action? People have a strong tendency to form shared task representations when co-acting - i.e. they take into account what those around them are doing or are expected to do. There is a level at which individual actions and those of co-actors are represented in a functionally equivalent way, as proposed by the "common coding" framework: humans can code the actions of others in terms of their goals, e.g., when they imitate their actions (Bekkering et al., 2000). Interestingly, goal sharing has been shown to improve motor accuracy and enhance the sense of agency for self-generated and observed actions, compared to a condition without goal sharing (Hayashida et al., 2021). A shared intention between co-actors (a decider and a follower) thus increases the sense of agency of each (van der Wel, 2015; van der Wel et al., 2012). Similarly, in a driving automation experiment, Wen et al. (2019) found that a driver's sense of agency can be maintained at a high level if the automated co-actor shares the driver's intention and the joint action achieves good performance (Wen et al., 2019). 
Thus, the process of multiple integration put forward in the construction of the individual sense of control would also be at work in our joint actions. However, while this integration mechanism is broadly similar, the nature of the information to which we have access and its reliability are radically different, so that the weighting of available cues is significantly different in joint and individual actions. Indeed, because people have access to perceptual, but not sensory reafferent, information about their partners' actions, perceptual predictions likely play a more important role than sensorimotor predictions in the experience of agency in social context (Pacherie, 2012; van der Wel et al., 2012).

Finally, it should be noted that, while the social agency continuum mentioned above (Silver et al., 2020) precisely captures the different nuances of agentive experience in social interaction, it remains silent on the place of mediated agency. Mediated agency corresponds to actions performed by humans on the basis of a machine-mediated decision (Le Goff et al., 2015). If this category of mediated agency is not often addressed, it may be because machinehuman interaction is often considered outside the sphere of social interactions. However, and as mentioned above, we believe that repositioning human-AI interactions on this continuum is relevant because of the characteristics endorsed by AI, such as autonomy and, to some extent, intentionality.

\section{How to improve Human-AI interactions?}

In this section, we discuss the field of eXplainable Artificial Intelligence (XAI), a research area that attempts to make AI more readable and transparent to human agents by producing 
explanations on how AI makes decisions. We suggest that studying social interactions and understanding the development of human sense of agency in joint actions can help determine the content of explanations to be implemented in AI with the goal of improving human-AI interactions. In particular, since AI can be considered an intentional system, we suggest that providing access to different levels of intention (proximal and distal) implemented by AI could help restore human operators' sense of agency, improve their confidence in the decisions made by artificial agents, and ultimately increase acceptability towards such agents.

\subsection{EXplainable Artificial Intelligence (XAI)}

The lack of transparency in many AI techniques discussed above has led to a growing interest in building explanations into AI systems to make their behavior interpretable and understandable (Putnam \& Conati, 2019). What is now called eXplainable Artificial Intelligence (XAI) was first introduced in 1988 by Moore and Swartout, demonstrating a fairly early ambition for generating explanations related to the internal processes of a system (van Lent et al., 2004). Thus, an explainable Artificial Intelligence is one that generates details or reasons to make its operation clear or easy to understand (Arrieta et al., 2019).

Current work in XAI aims to make AI techniques more transparent in hopes of improving human-AI interactions and, more importantly, increasing user confidence. In addition, providing information can also develop users' understanding of the learning mechanism of an intelligent system (Putnam \& Conati, 2019). It has been proposed the principle of "meaningful human control" over autonomous agent (Santoni de Sio \& van den Hoven, 
2018). According to this principle, humans should ultimately remain in control of, and thus morally responsible for, algorithm decisions. This principle of "meaningful human control" is applicable provided that two conditions are met. First, a "tracking" condition whereby the system must be able to respond to both the relevant moral reasons of the humans designing and deploying the system and the relevant facts of the environment in which the system operates. Second, a "tracing" condition, according to which the system must be designed in such a way as to ensure that the outcome of its operations can always be traced back (Santoni de Sio \& van den Hoven, 2018).

Interestingly, among the different types of algorithms involving human-AI interactions, those aiming at recommending a choice to a user - i.e. recommendation systems - have started to integrate this notion of explanation in their algorithms. In this domain, explanations correspond to a description of the selected item that helps the user to "understand the qualities of the item well enough to decide whether or not it is relevant to them" (Tintarev \& Masthoff, 2012). Some research has shown that presenting explanations to users can increase not only the persuasiveness of recommended items but also users' trust and satisfaction with the recommendation system. Based on these results, guidelines have been developed for the design and evaluation of explanations for recommendation systems (Tintarev \& Masthoff, 2010)

If the will to make AI systems more intelligible for humans is current, many uncertainties remain about how to make AI explainable. Indeed, wanting to make AI explainable and knowing how to do so are two very different issues. Miller (2018) was one of the first to make the connection between XAI and the social sciences, arguing that the field should build on 
existing research in this field, from philosophy to cognitive and social psychology. He also proposed that much of the work on XAI are based on researchers' intuition about what constitutes a "good explanation", i.e. one that disregards existing knowledge about individuals' cognitive functioning (Miller, 2018; see also, Bonnefon, Shariff, and Rahwan 2016 , for a call to rely on people's moral intuitions in the field of driverless vehicles). Mueller (2020), on the other hand, pointed out the lack of a scientific approach in the implementation of some XAI solutions. In particular, XAI systems are frequently algorithm-driven, that is, they start and end with an algorithm that implements a basic untested idea about explainability. The problem is that these systems are often not tested to determine whether the algorithm helps users achieve any goal, and so their explainability remains unproven (Mueller et al., 2020).

Finally, it should be noted that, since its emergence, the notion of XAI has often been invoked in work aimed at improving user confidence and satisfaction. However, XAI has paid little attention to an essential dimension of human cognition, namely the users' sense of control. What would an XAI that promotes a sense of control in human operators look like? We believe that knowledge of the mechanisms underlying sense of control in joint action could shed new light on the nature of useful information to communicate to an AI user, and thus contribute to thinking about XAI, and autonomous artificial systems in general. 


\subsection{Artificial Intelligence and intentionality}

We recalled above that AI has a certain degree of decision-making autonomy. Interestingly, an autonomous technology can give the impression to the human operator that it has intentions. The notion of "intentional stance" (Dennett 1988) refers to a strategy of interpreting the behavior of an entity (person, animal, artifact) by treating it as if it were a rational agent that governs its action choices by taking into account its beliefs and desires (Dennett, 2009). An intrinsic disposition to attribute mental states (Kovács et al., 2010), combined with repeated exposure to intentional explanations during childhood, make humans experts at adopting the "intentional stance" when it comes to interpreting and predicting the behaviors of others (Perez-Osorio \& Wykowska, 2020). Some experimental studies have shown that humans also adopt the intentional stance when interacting with robots, especially humanoids (Gazzola et al., 2007; Oberman et al., 2007). In particular, people may interpret robots in the same way as goal-directed agents (Wykowska et al., 2014), and they adopt an intentional stance toward the robot to a similar extent as they do when observing other humans (Abubshait et al., 2021; Thellman et al., 2017).

We argue here that, because of (i) the particular characteristics of AI in the landscape of artificial systems, and (ii) the frequent adoption of an intentional stance towards robots, the interactions that human operators have with AI share some properties with human social interactions. The intentional characteristics of $\mathrm{AI}$ thus lead us to consider human-AI interactions in the light of human-human relations. Since making the intentions of others clear and legible is important for human-human coordination, we will argue that doing the same with AI intentions is an essential condition for building reliable human-AI interactions. 
3.3. Improving human-AI interactions: displaying intentions along the goal hierarchy

We have seen that automation can significantly affect the sense of agency of human operators, not only because automation deprives the operator of the possibility of making choices themself, but also because the decisions made by automated systems - in particular autonomous and intentional systems - lack transparency, are inaccessible, or are not explicable at all (Norman et al., 1990). Such opacity makes it difficult for the operator to relate the system's intention to actual state and to predict the sequence of events that will occur. Making the decisions of artificial systems more transparent, even "explaining" them, is therefore a crucial issue, not only for the quality of the interaction between operators and these systems - on which key dimensions such as operational performance and safety depend - , but also for the acceptability of operators towards these systems. Here, we argue that the format and content of explanation could benefit from the study of social interactions in cognitive science.

\section{The variety of intentions}

As we have seen for joint actions, the sense of agency of the co-authors of a joint action increases when the co-authors share their intentions (Atmaca et al. 2008; Sebanz et al. 2003, 2005; Wegner et al. 2004; van der Wel 2015; van der Wel et al. 2012, see also Le Bars et al. 2020). An obvious solution for the improvement of human-machine interactions would be to share the AI's intentions with the operator. However, the question remains as to the modality 
of this sharing and, more critically, the format of the shared intention. Indeed, intention is not of a unique type but can be broken down into different types and subtypes. Crucially, some types of intentions might be easier to share than others.

Various models of goal-directed action, bringing together theoretical work on intentionality and empirical work on representations and motor control, have been proposed to account for the variety of intentions. One of the most influential distinguishes three classes of intentions - distal, proximal, and motor - according to the level they occupy in the hierarchy of action control (Pacherie (2008); see Chambon et al., $(2011,2017)$ for empirical implementation). The central idea of this model, called "DPM model", is that action control is the result of integrated and coordinated activity between these levels of intention (Mylopoulos \& Pacherie, 2019). The DPM model specifies the representational and functional profiles of each type of intention as follows:

- Distal intentions (D-intentions) instantiate the most abstract level of representation of the action to be performed. D-intentions concern actions of endogenous origin that have a long-term, complex or abstract goal. Once formed, they also have the function of initiating a planning process - especially when the goal to be achieved is complex and novel - or, when dealing with goals for which one already has a plan of action, to retrieve this plan from memory (Khamassi \& Pacherie, 2018). Dintentions can thus be both the result of a process of deliberation about ends (what to do?) and the starting point of processes of deliberation on means (how to do it?).

- Proximal intentions (P-intentions) instantiate finer and more immediate representations of the action to be performed. A proximal intention specifies the 
proposed action by anchoring it in the present situation and by selecting motor programs adapted to this situation. The representation of the action is further specified by the integration of perceptual information about the situation which will constitute as many constraints on the choice of the motor program to be implemented.

- Motor intentions (M-intentions) instantiate detailed sensorimotor representations of movements in space and the targets of those movements. M-intentions can be seen as being the action specification process, since they guide the action in real time: they encode action goals together with the motoric means for achieving them and do so in a motoric format directly suitable to action execution - meaning that only those attributes or properties of objects that are necessary for the specification of movements are encoded.

The meaning of "intention" clearly depends on which stages of the action specification process are being discussed. Some of the functions attributed to intentions are typically played in the period between the initial formation of the intention itself and the initiation of the action (D-intention level). In contrast, other functions - in particular, their role in guiding and monitoring the action - are played in the period between the initiation of the action and its completion (M-intention level). Communicating AI's intentions at either of these levels can induce beneficial changes in the human operator's self-agency. Thus, some studies have shown that successfully decoding operators' motor intentions for manual action (via a BrainComputer Interface) and transmitting then to the hand of humanoid robots induces in 
operators a sense of agency over the robot hand and an illusion of bodily ownership over it (Alimardani et al., 2013; Perez-Marcos et al., 2009; Slater et al., 2009). Interestingly, during robot embodiment, people generally do not feel that they are sharing control with the robot; instead, they feel that the robot's hand is a part of their body and is under the full control of their own (Wen et al., 2019).

The previously mentioned study by Le Goff and colleagues (2018) aimed to directly investigate how the predictability of a system - and specifically how messages conveying the system's intent - can influence the development of agency in supervisory situations. The idea was to provide information about what the automated system is about to do next, and to observe whether this information improves user's level of acceptability of the system as well as their level of control. The results suggest that displaying the system's intentions at this level is an effective approach to improving users' sense of control and acceptability towards the system. This study further shows that providing information about a higher level of intention (P-intentions) than just the level of motor intention (M-intentions), increases the feeling of control of the action produced by an automated system, above and beyond improving bodily ownership.

As mentioned earlier, to the extent that we interact with a system that makes decisions, the initiation of the action is most often automatically attributed to the system and, in this case, bodily ownership of the action is irrelevant. Human-machine interactions are therefore particularly concerned with explicability at the most abstract (i.e. less concrete) levels of the action control hierarchy. Reflecting this concern for higher levels of action representation, Vantrepotte et al., (2021) recently explored the effect of communicating metacognitive 
information on enhancing the feeling of control of participants interacting with a piloting assistance system. In particular, they investigated whether communicating the system's confidence in its decision (rather than just the decision itself) could increase the system's intelligibility and acceptability. The results showed that communicating the confidence - i.e. the degree of uncertainty - associated with the system choice not only enhanced the user's sense of control, but also gave them greater confidence in the decision, and improved their performance (Vantrepotte et al., 2021).

\section{Communicating the system's intention to promote mind alignment}

Gallotti and colleagues (2017) recently proposed that the nature of the information exchanged between interacting agents is crucial in determining the social or non-social nature of a human interaction, rather than the existence or absence of a shared goal (Gallotti et al., 2017). Their central claim is that social cognition is about the dynamic process of aligning individual minds, even in the absence of a shared goal. Such "mind alignment" emerges in social interactions involving the reciprocal exchange of information by which individuals adjust their minds and bodies in a gradual manner. To understand the nature of social interactions, the authors therefore propose to study how individuals align their words and thoughts, body postures and movements, in order to take into account the member(s) of the interaction and fully exploit socially relevant information.

Relatedly, we propose that the informational content to be conveyed to foster such mind alignment in HMIs is the intention of the AI system at either level of the intention hierarchy (distal, proximal, motor), depending on the need and specificity of the interaction at hand 
(whether to improve bodily ownership, task prediction, sense of control, and/or acceptability towards the artificial agent). A confidence measure associated with this intention, quantifying the extent to which the intention is likely to achieve the intended goal, would be a useful complement to the content of this communication. Future experiments should be conducted test whether and how communicating intentions at the most abstract levels (D-intentions) of an AI system improves users' sense of control over the effects of AI decisions, as well as the level of acceptability towards the artificial system.

Knowledge gained from cognitive science about how human operators develop a reliable sense of agency in social contexts can help decide what kind of explanation we want to provide in human-AI interactions. In particular, making AI intentions accessible at different levels of complexity can shift the cursor of experience in human-machine interactions from mediated agency to true joint agency (Silver et al., 2020). Doing so can make interactions with AI more social, and ultimately do justice to the novelty of AI's status among artificial systems. Reconsidering the human-AI relationship as a particular type of social interaction, and thus AI as a partner to cooperate with rather than a tool, offers a valuable perspective for improving interactions between humans and advanced artificial systems, both present and future. 


\section{Conclusions and perspectives}

This review shed new light on the study of human-AI interaction by arguing that the future of new technologies must be thought in the light of knowledge about human cognition, and in particular about the cognitive processes at play in social context.

First, we emphasized the importance of the sense of agency in the way human agents perceive and evaluate their own actions. We suggested that the sense of agency could be a good candidate to explain the difficulties observed in human-automated system interactions. We have shown that advances in automation technologies can disrupt the development of the experience of agency and that this disruption can have important operational consequences. First, decrease in the sense of control when interacting with highly automated systems has been shown to threat the acceptability of the system's decisions by human operators. A diminished sense of control can also lead to decreased involvement and motivation in the task at hand, as well as a decreased willingness to exert effort. Finally, a reduced sense of agency is known to have negative impact on attention and memory, and therefore on operational performance.

We then described how the sense of agency develops along the intention-action-effect causal chain in two complementary dimensions, one retrospective, the other prospective. We presented the sense of agency as a flexible mechanism that can be modulated under certain conditions, and discussed how the automation of all or part of the intention-action-effect causal chain is likely to interact with these conditions. We drew some parallels between the degree of operator involvement and the level of automation of a task, the importance of the temporal unfolding of voluntary actions and the potential latency effects induced by 
automation, the impact of performance on the sense of control and the increased levels of performance induced by automation, and finally between the facilitation of action choice and the readability of the choices of the automated system.

It is now clear that the evolution of technological systems generates new challenges for the human operator experience, which are directly related to the nature of our relationship with technology. We have therefore suggested that understanding the relationship between automation and the sense of control is essential to optimizing human-automation interactions. Furthermore, with the advent of Artificial Intelligence, technology will soon no longer be seen as a mere tool at the disposal of the human operator, but as an integral member of the interaction. We have thus highlighted the changes brought about by the advent of AI as a "partner" in our relationship with artificial agents, and the potential impact of these changes on human agency. We have detailed some of the existing differences between automated systems and Artificial Intelligence. The characteristics of complexity, non-determinism and autonomy lead to an increasing opacity of these systems for the human operator, and ultimately give AI a completely different role from the one initially assigned to the machine. In particular, these characteristics have allowed us to raise the question of the readability of $\mathrm{AI}$ in a context of joint action.

Finally, we addressed the field of XAI through its goal of increasing the readability of AI algorithms by adding targeted explanations. An important contribution to this area could be to determine the content of explanations to be implemented in AI by understanding the development of the sense of human control in joint actions. What would an XAI that promotes a sense of control in human operators look like? We have shown that an 
autonomous technology has characteristics that encourage the human operator to view it as having intentions. The intentional characteristics of AI led us to consider human-AI interactions in the light of human-human relations. Since making the intentions of others clear and legible is important for human-human coordination, we argued that doing the same with AI intentions is an essential condition for building reliable human-AI interactions. We suggested that sharing $\mathrm{AI}$ intentions with the operator is a solution to consider for increasing the sense of control of human operators, focusing on a model that distinguishes different classes of intentions - distal, proximal, and motor - according to the level they occupy in the hierarchy of action control. The central idea of this model, called "DPM model", is that action control is the result of an integrated and coordinated activity between these different levels of intention. We discussed the function of each level of intention and made predictions about the effect of communicating the system's intention to any of its levels, both in terms of benefit changes to the human operator's agency but also to the operator's levels of acceptability and confidence in the AI's decisions.

To conclude, insights from cognitive science about how human operators develop a reliable sense of agency in social contexts can help determine the kind of explanation we want to communicate in human-AI interactions. Reconsidering the relationship between humans and $\mathrm{AI}$ as a particular type of social interaction, and thus $\mathrm{AI}$ as a partner to cooperate with rather than a simple tool, offers a valuable perspective for improving interactions between humans and advanced artificial systems, both in the present and in the future. 


\section{Declarations}

Conflicts of interest. The authors have no relevant financial or non-financial interests to disclose.

Acknowledgments. This work was supported by Office National d'Etudes et de Recherches Aérospatiales (ONERA), the Agence de l'Innovation de Défense (AID) (DGA 202065 0022), and by a department-wide grant from the Agence Nationale de la Recherche (ANR-17-EURE-0017, EUR FrontCog). This work has received support under the program «Investissements d'Avenir» launched by the French Government and implemented by ANR (ANR-10-IDEX-0001-02 PSL). V.C. was supported by the French National Research Agency (ANR-16-CE37-0012-01 and ANR-19-CE37-0014-01). 


\section{References}

Abubshait, A., Pérez-Osorio, J., De Tommaso, D., \& Wykowska, A. (2021). Collaboratively framed interactions increase the adoption of intentional stance towards robots [Preprint]. Open Science Framework. https://doi.org/10.31219/osf.io/zwqfa

Alimardani, M., Nishio, S., \& Ishiguro, H. (2013). Humanlike robot hands controlled by brain activity arouse illusion of ownership in operators. Scientific Reports, 3(1), 2396. https://doi.org/10.1038/srep02396

American Psychological Association. (2020). Artificial Intelligence. https://dictionary.apa.org/artificial-intelligence

Apperly, I. A., \& Butterfill, S. A. (2009). Do humans have two systems to track beliefs and belief-like states? Psychological Review, 116(4), 953-970. https://doi.org/10.1037/a0016923

Arrieta, A. B., Díaz-Rodríguez, N., Del Ser, J., Bennetot, A., Tabik, S., Barbado, A., García, S., Gil-López, S., Molina, D., Benjamins, R., Chatila, R., \& Herrera, F. (2019). Explainable Artificial Intelligence (XAI): Concepts, Taxonomies, Opportunities and Challenges toward Responsible AI. ArXiv:1910.10045 [Cs].
[ http://arxiv.org/abs/1910.10045

Atmaca, S., Sebanz, N., Prinz, W., \& Knoblich, G. (2008). Action co-representation: The joint SNARC effect. Social Neuroscience, 3(3-4), 410-420. https://doi.org/10.1080/17470910801900908

Bandura, A. (1999). Handbook of Personality, Second Edition: Theory and Research. Elsevier. 
Bandura, A., Barbaranelli, C., Caprara, G. V., \& Pastorelli, C. (1996). Mechanisms of Moral Disengagement in the Exercise of Moral Agency. 11.

Barlas, Z., \& Kopp, S. (2018). Action Choice and Outcome Congruency Independently Affect Intentional Binding and Feeling of Control Judgments. Frontiers in Human Neuroscience, 12, 137. https://doi.org/10.3389/fnhum.2018.00137

Barlas, Z., \& Obhi, S. S. (2013). Freedom, choice, and the sense of agency. Frontiers in Human Neuroscience, 7, 514. https://doi.org/10.3389/fnhum.2013.00514

Baronas, A.-M. K., \& Louis, M. R. (1988). Restoring a Sense of Control during Implementation: How User Involvement Leads to System Acceptance. MIS Quarterly, 12(1), 111-124. https://doi.org/10.2307/248811

Bednark, J. G., \& Franz, E. A. (2014). Agency attribution: Event-related potentials and outcome monitoring. Experimental Brain Research, 232(4), 1117-1126. https://doi.org/10.1007/s00221-014-3821-4

Bekkering, H., Wohlschlager, A., \& Gattis, M. (2000). Imitation of Gestures in Children is Goal-directed. The Quarterly Journal of Experimental Psychology Section A, 53(1), 153-164. https://doi.org/10.1080/713755872

Berberian, B., (2019). Man-Machine teaming: A problem of Agency. IFAC-PapersOnLine, 51(34), 118-123. https://doi.org/10.1016/j.ifacol.2019.01.049

Berberian, B., Le Blaye, P., Schulte, C., Kinani, N., \& Sim, P. R. (2013). Data Transmission Latency and Sense of Control. In D. Harris (Ed.), Engineering Psychology and Cognitive Ergonomics. Understanding Human Cognition (Vol. 8019, pp. 3-12). Springer Berlin Heidelberg. https://doi.org/10.1007/978-3-642-39360-0_1 
Berberian, B., Sarrazin, J.-C., Le Blaye, P., \& Haggard, P. (2012). Automation Technology and Sense of Control: A Window on Human Agency. PLoS ONE, 7(3), e34075. https://doi.org/10.1371/journal.pone.0034075

Beyer, F., Sidarus, N., Bonicalzi, S., \& Haggard, P. (2017). Beyond self-serving bias: Diffusion of responsibility reduces sense of agency and outcome monitoring. Social Cognitive and Affective Neuroscience, 12(1), 138-145. https://doi.org/10.1093/scan/nsw160

Bigenwald, A. (2018). THE LEGAL CHALLENGE OF CIVIL LIABILITY IN THE AGE OF ARTIFICIAL INTELLIGENCE : THE AUTONOMOUS ROBOT: PERSON, SLAVE OR MACHINE? 18.

Bigenwald, A., \& Chambon, V. (2019). Criminal Responsibility and Neuroscience: No Revolution Yet. Frontiers in Psychology, 10, 1406. https://doi.org/10.3389/fpsyg.2019.01406

Blakemore, S.-J., Frith, C. D., \& Wolpert, D. M. (1999). Spatio-Temporal Prediction Modulates the Perception of Self-Produced Stimuli. Journal of Cognitive Neuroscience, 11(5), 551-559. https://doi.org/10.1162/089892999563607

Böckler, A., Knoblich, G., \& Sebanz, N. (2012). Effects of a coactor's focus of attention on task performance. Journal of Experimental Psychology: Human Perception and Performance, 38(6), 1404-1415. https://doi.org/10.1037/a0027523

Bolt, N. K., \& Loehr, J. D. (2017). The predictability of a partner's actions modulates the sense of joint agency. Cognition, 161, 60-65. https://doi.org/10.1016/j.cognition.2017.01.004 
Bonnefon, J.-F., Shariff, A., \& Rahwan, I. (2016). The social dilemma of autonomous vehicles. Science, 352(6293), 1573-1576. https://doi.org/10.1126/science.aaf2654

Botvinick, M., Ritter, S., Wang, J. X., Kurth-Nelson, Z., Blundell, C., \& Hassabis, D. (2019). Reinforcement Learning, Fast and Slow. Trends in Cognitive Sciences, 23(5), 408422. https://doi.org/10.1016/j.tics.2019.02.006

Brandi, M.-L., Kaifel, D., Bolis, D., \& Schilbach, L. (2019). The Interactive Self - A Review on Simulating Social Interactions to Understand the Mechanisms of Social Agency. ICom, 18(1), 17-31. https://doi.org/10.1515/icom-2018-0018

Caspar, E. A., Christensen, J. F., Cleeremans, A., \& Haggard, P. (2016). Coercion Changes the Sense of Agency in the Human Brain. Current Biology, 26(5), 585-592. https://doi.org/10.1016/j.cub.2015.12.067

Caspar, E. A., Cleeremans, A., \& Haggard, P. (2018). Only giving orders? An experimental study of the sense of agency when giving or receiving commands. PLOS ONE, 13(9), e0204027. https://doi.org/10.1371/journal.pone.0204027

Chambon, V., Domenech, P., Jacquet, P. O., Barbalat, G., Bouton, S., Pacherie, E., Koechlin, E., \& Farrer, C. (2017). Neural coding of prior expectations in hierarchical intention inference. Scientific Reports, 7(1), 1278. https://doi.org/10.1038/s41598-017-01414-y

Chambon, V., Domenech, P., Pacherie, E., Koechlin, E., Baraduc, P., \& Farrer, C. (2011). What Are They Up To? The Role of Sensory Evidence and Prior Knowledge in Action $\begin{array}{llll}\text { Understanding. } & P L O S & \text { ONE, } & 6(2),\end{array}$ https://doi.org/10.1371/journal.pone.0017133 
Chambon, V., \& Haggard, P. (2012). Sense of control depends on fluency of action selection, not motor performance. Cognition, 125(3), 441-451. https://doi.org/10.1016/j.cognition.2012.07.011

Chambon, V., \& Haggard, P. (2013). Premotor or Ideomotor: How Does the Experience of Action Come About? (pp. 359-380). https://doi.org/10.7551/mitpress/9780262018555.001.0001

Chambon, V., Moore, J. W., \& Haggard, P. (2015). TMS stimulation over the inferior parietal cortex disrupts prospective sense of agency. Brain Structure \& Function, 220(6), 3627-3639. https://doi.org/10.1007/s00429-014-0878-6

Chambon, V., Sidarus, N., \& Haggard, P. (2014). From action intentions to action effects: How does the sense of agency come about? Frontiers in Human Neuroscience, 8. https://doi.org/10.3389/fnhum.2014.00320

Chambon, V., Wenke, D., Fleming, S. M., Prinz, W., \& Haggard, P. (2013). An Online Neural Substrate for Sense of Agency. Cerebral Cortex, 23(5), 1031-1037. https://doi.org/10.1093/cercor/bhs059

Christoffersen, K., \& Woods, D. (2002). How to make automated systems team players. In Advances in Human Performance and Cognitive Engineering Research (Vol. 2, pp. 112). Elsevier. https://doi.org/10.1016/S1479-3601(02)02003-9

Ciardo, F., De Tommaso, T., Beyer, F., \& Wykowska, A. (2018). Reduced Sense of Agency in Human-Robot interaction. https://qmro.qmul.ac.uk/xmlui/handle/123456789/56277

Dekker, S. W. A., \& Woods, D. D. (2002). MABA-MABA or Abracadabra? Progress on Human-Automation Co-ordination. Cognition, Technology \& Work, 4(4), 240-244. https://doi.org/10.1007/s101110200022 
Dennett, D. (2009). Intentional Systems Theory. Oxford University Press. https://doi.org/10.1093/oxfordhb/9780199262618.003.0020

Di Costa, S., Théro, H., Chambon, V., \& Haggard, P. (2018). Try and try again: Post-error boost of an implicit measure of agency. Quarterly Journal of Experimental Psychology, 71(7), 1584-1595. https://doi.org/10.1080/17470218.2017.1350871

Ebert, J. P., \& Wegner, D. M. (2010). Time warp: Authorship shapes the perceived timing of actions and events. Consciousness and Cognition, 19(1), 481-489. https://doi.org/10.1016/j.concog.2009.10.002

Eitam, B., Kennedy, P. M., \& Tory Higgins, E. (2013). Motivation from control. Experimental Brain Research, 229(3), 475-484. https://doi.org/10.1007/s00221-012$3370-7$

Endo, S., Fröhner, J., Musić, S., Hirche, S., \& Beckerle, P. (2020). Effect of External Force on Agency in Physical Human-Machine Interaction. Frontiers in Human Neuroscience, 14, 114. https://doi.org/10.3389/fnhum.2020.00114

Endsley, M. R. (1999). Level of automation effects on performance, situation awareness and workload in a dynamic control task. Ergonomics, 42(3), 462-492. https://doi.org/10.1080/001401399185595

Endsley, M. R., \& Kiris, E. O. (1995). The Out-of-the-Loop Performance Problem and Level of Control in Automation. Human Factors: The Journal of the Human Factors and Ergonomics Society, 37(2), 381-394. https://doi.org/10.1518/001872095779064555

Ephrath, A. R., \& Young, L. R. (1981). Monitoring vs. Man-in-the-Loop Detection of Aircraft Control Failures. In J. Rasmussen \& W. B. Rouse (Eds.), Human Detection and 
Diagnosis of System Failures (pp. 143-154). Springer US. https://doi.org/10.1007/978-1-4615-9230-3_10

Farrer, C., Valentin, G., \& Hupé, J. M. (2013). The time windows of the sense of agency. Consciousness and Cognition, 22(4), 1431-1441. https://doi.org/10.1016/j.concog.2013.09.010

Forsyth, D. R., Zyzniewski, L. E., \& Giammanco, C. A. (2002). Responsibility Diffusion in Cooperative Collectives. Personality and Social Psychology Bulletin, 28(1), 54-65. https://doi.org/10.1177/0146167202281005

Foxlin, E. (2002). Motion Tracking Requirements and Technologies. In Handbook of Virtual Environments. CRC Press.

Gallotti, M., Fairhurst, M. T., \& Frith, C. D. (2017). Alignment in social interactions. Consciousness and Cognition, 253-261. https://doi.org/10.1016/j.concog.2016.12.002

Gallotti, M., \& Frith, C. D. (2013). Social cognition in the we-mode. Trends in Cognitive Sciences, 17(4), 160-165. https://doi.org/10.1016/j.tics.2013.02.002

Garbarini, F., Mastropasqua, A., Sigaudo, M., Rabuffetti, M., Piedimonte, A., Pia, L., \& Rocca, P. (2016). Abnormal Sense of Agency in Patients with Schizophrenia: Evidence from Bimanual Coupling Paradigm. Frontiers in Behavioral Neuroscience, 10. https://doi.org/10.3389/fnbeh.2016.00043

Gazzola, V., Rizzolatti, G., Wicker, B., \& Keysers, C. (2007). The anthropomorphic brain: The mirror neuron system responds to human and robotic actions. NeuroImage, 35(4), 1674-1684. https://doi.org/10.1016/j.neuroimage.2007.02.003 
Grynszpan, O., Sahaï, A., Hamidi, N., Pacherie, E., Berberian, B., Roche, L., \& Saint-Bauzel, L. (2019). The sense of agency in human-human vs human-robot joint action. $\begin{array}{llll}\text { Consciousness } & \text { and } & \text { Cognition, } & 75,\end{array}$ https://doi.org/10.1016/j.concog.2019.102820

Haggard, P. (2017). Sense of agency in the human brain. Nature Reviews Neuroscience, 18(4), 196-207. https://doi.org/10.1038/nrn.2017.14

Haggard, P., \& Chambon, V. (2012). Sense of agency. Current Biology, 22(10), R390-R392. https://doi.org/10.1016/j.cub.2012.02.040

Haggard, P., Clark, S., \& Kalogeras, J. (2002). Voluntary action and conscious awareness. Nature Neuroscience, 5(4), 382-385. https://doi.org/10.1038/nn827

Hallett, N. (2018). Psychiatric evidence in Diminished Responsibility. The Journal of Criminal Law, 82(6), 442-456. https://doi.org/10.1177/0022018318801677

Hayashida, K., Nishi, Y., Osumi, M., Nobusako, S., \& Morioka, S. (2021). Goal sharing with others modulates the sense of agency and motor accuracy in social contexts. PLOS ONE, 16(2), e0246561. https://doi.org/10.1371/journal.pone.0246561

Hindriks, K., Wiggers, P., Jonker, C., \& Haselager, W. (2011). Towards a Computational Model of the Self-attribution of Agency. In K. G. Mehrotra, C. K. Mohan, J. C. Oh, P. K. Varshney, \& M. Ali (Eds.), Modern Approaches in Applied Intelligence (pp. 295305). Springer. https://doi.org/10.1007/978-3-642-21822-4_30

Hon, N., Poh, J.-H., \& Soon, C.-S. (2013). Preoccupied minds feel less control: Sense of agency is modulated by cognitive load. Consciousness and Cognition, 22(2), 556-561. https://doi.org/10.1016/j.concog.2013.03.004 
Hon, N., \& Yeo, N. (2021). Having a sense of agency can improve memory. Psychonomic Bulletin \& Review, 28(3), 946-952. https://doi.org/10.3758/s13423-020-01849-x

International Civil Aviation Organization. (2017). International Civil Aviation Organization, Safety Report (p. (p. 25).).

Jammes, Y., Behr, M., Llari, M., Bonicel, S., Weber, J. P., \& Berdah, S. (2017). Emergency braking is affected by the use of cruise control. Traffic Injury Prevention, 18(6), 636641. https://doi.org/10.1080/15389588.2016.1274978

Jeannerod, M. (2003). The mechanism of self-recognition in humans. Behavioural Brain Research, 142(1), 1-15. https://doi.org/10.1016/S0166-4328(02)00384-4

Kaber, D. B., \& Endsley, M. R. (1997). Out-of-the-loop performance problems and the use of intermediate levels of automation for improved control system functioning and safety. Process Safety Progress, 16(3), 126-131. https://doi.org/10.1002/prs.680160304

Kawabe, T. (2013). Inferring sense of agency from the quantitative aspect of action outcome. Consciousness and Cognition, 22(2), 407-412. https://doi.org/10.1016/j.concog.2013.01.006

Kessel, C. J., \& Wickens, C. D. (1982). The Transfer of Failure-Detection Skills between Monitoring and Controlling Dynamic Systems. Human Factors: The Journal of the Human Factors and Ergonomics Society, 24(1), 49-60. https://doi.org/10.1177/001872088202400106

Khamassi, M., \& Pacherie, E. (2018). L’ACTION. In Collins, T., Andler, D., Tallon-Baudry, \& C. (Eds.), La cognition: Du neurone à la société. Gallimard. https://hal.archivesouvertes.fr/hal-02324111 
Kovács, Á. M., Téglás, E., \& Endress, A. D. (2010). The Social Sense: Susceptibility to Others' Beliefs in Human Infants and Adults. Science, 330(6012), 1830-1834. https://doi.org/10.1126/science.1190792

Kühn, S., Nenchev, I., Haggard, P., Brass, M., Gallinat, J., \& Voss, M. (2011). Whodunnit? Electrophysiological Correlates of Agency Judgements. PLoS ONE, 6(12), e28657. https://doi.org/10.1371/journal.pone.0028657

Le Bars, S., Devaux, A., Nevidal, T., Chambon, V., \& Pacherie, E. (2020). Agents' pivotality and reward fairness modulate sense of agency in cooperative joint action. Cognition, 195, 104117. https://doi.org/10.1016/j.cognition.2019.104117

Le Goff, K., Rey, A., \& Berberian, B. (2015). Toward a Model for Effective HumanAutomation Interaction: The Mediated Agency. In V. G. Duffy (Ed.), Digital Human Modeling. Applications in Health, Safety, Ergonomics and Risk Management: Ergonomics and Health (pp. 274-283). Springer International Publishing. https://doi.org/10.1007/978-3-319-21070-4_28

Le Goff, K., Rey, A., Haggard, P., Oullier, O., \& Berberian, B. (2018). Agency modulates interactions with automation technologies. Ergonomics, 61(9), 1282-1297. https://doi.org/10.1080/00140139.2018.1468493

Li, P., Han, C., Lei, Y., Holroyd, C. B., \& Li, H. (2011). Responsibility modulates neural mechanisms of outcome processing: An ERP study. Psychophysiology, 48(8), 11291133. https://doi.org/10.1111/j.1469-8986.2011.01182.x

MacKenzie, I. S., \& Ware, C. (1993). Lag as a determinant of human performance in interactive systems. Proceedings of the INTERACT '93 and CHI'93 Conference on 
Human Factors in Computing 488-493. https://doi.org/10.1145/169059.169431

McCarthy, J., Minsky, M. L., Rochester, N., \& Shannon, C. E. (1955). A Proposal for the Dartmouth Summer Research Project on Artificial Intelligence, August 31, 1955 (No. 4). 27(4), 12-12. https://doi.org/10.1609/aimag.v27i4.1904

McNeese, N. J., Demir, M., Cooke, N. J., \& Myers, C. (2018). Teaming With a Synthetic Teammate: Insights into Human-Autonomy Teaming. Human Factors, 60(2), 262273. https://doi.org/10.1177/0018720817743223

Metcalfe, J., Eich, T. S., \& Miele, D. B. (2013). Metacognition of agency: Proximal action and distal outcome. Experimental Brain Research, 229(3), 485-496. https://doi.org/10.1007/s00221-012-3371-6

Metcalfe, J., \& Greene, M. J. (2007). Metacognition of agency. Journal of Experimental Psychology: General, 136(2), 184-199. https://doi.org/10.1037/0096-3445.136.2.184

Miller, T. (2018). Explanation in Artificial Intelligence: Insights from the Social Sciences. ArXiv:1706.07269 [Cs]. http://arxiv.org/abs/1706.07269

Moore, J. W., \& Fletcher, P. C. (2011). Sense of agency in health and disease: A review of cue integration approaches. Consciousness and Cognition, 21(1), 59-68. https://doi.org/10.1016/j.concog.2011.08.010

Moore, \& Obhi, S. S. (2012). Intentional binding and the sense of agency: A review. $\begin{array}{lll}\text { Consciousness } \quad \text { Cognition, } & \text { 21(1), 546-561. }\end{array}$ https://doi.org/10.1016/j.concog.2011.12.002 
Moore, J. W., Wegner, D. M., \& Haggard, P. (2009). Modulating the sense of agency with external cues. Consciousness and Cognition, 18(4), 1056-1064. https://doi.org/10.1016/j.concog.2009.05.004

Mueller, S. T., Veinott, E. S., Hoffman, R. R., Klein, G., Alam, L., Mamun, T., \& Clancey, W. J. (2020). Principles of Explanation in Human-AI Systems. 11.

Mulder, M., Abbink, D. A., \& Boer, E. R. (2012). Sharing Control With Haptics: Seamless Driver Support From Manual to Automatic Control. Human Factors: The Journal of the Human Factors and Ergonomics Society, 54(5), 786-798. https://doi.org/10.1177/0018720812443984

Mylopoulos, M., \& Pacherie, E. (2019). Intentions: The dynamic hierarchical model revisited. WIREs Cognitive Science, 10(2), e1481. https://doi.org/10.1002/wcs.1481

Mynatt, C., \& Sherman, S. J. (1975). Responsibility attribution in groups and individuals: A direct test of the diffusion of responsibility hypothesis. Journal of Personality and Social Psychology, 32(6), 1111-1118. https://doi.org/10.1037/0022-3514.32.6.1111

Navarro, J., François, M., \& Mars, F. (2016). Obstacle avoidance under automated steering: Impact on driving and gaze behaviours. Transportation Research Part F: Traffic Psychology and Behaviour, 43, 315-324. https://doi.org/10.1016/j.trf.2016.09.007

Norman, D. A., Broadbent, D. E., Baddeley, A. D., \& Reason, J. (1990). The 'problem ' with automation: Inappropriate feedback and interaction, not 'over-automation.' Philosophical Transactions of the Royal Society of London. B, Biological Sciences, 327(1241), 585-593. https://doi.org/10.1098/rstb.1990.0101

Oberman, L. M., McCleery, J. P., Ramachandran, V. S., \& Pineda, J. A. (2007). EEG evidence for mirror neuron activity during the observation of human and robot actions: 
Toward an analysis of the human qualities of interactive robots. Neurocomputing, 70(13), 2194-2203. https://doi.org/10.1016/j.neucom.2006.02.024

Obhi, S. S., \& Hall, P. (2011). Sense of agency and intentional binding in joint action. Experimental Brain Research, 211(3-4), 655-662. https://doi.org/10.1007/s00221$011-2675-2$

Pacherie, E. (2007). The Sense of Control and the Sense of Agency. 13(1), 30.

Pacherie, E. (2008). The phenomenology of action: A conceptual framework. Cognition, 107(1), 179-217. https://doi.org/10.1016/j.cognition.2007.09.003

Pacherie, E. (2012). The Phenomenology of Joint Action: Self-Agency versus Joint Agency. In A. Seemann (Ed.), Joint Attention. The MIT Press. https://doi.org/10.7551/mitpress/8841.003.0017

Pacherie, E. (2014). How does it feel to act together? Phenomenology and the Cognitive Sciences, 13(1), 25-46. https://doi.org/10.1007/s11097-013-9329-8

Perez-Marcos, D., Slater, M., \& Sanchez-Vives, M. V. (2009). Inducing a virtual hand ownership illusion through a brain-computer interface. NeuroReport, 20(6), 589-594. https://doi.org/10.1097/WNR.0b013e32832a0a2a

Perez-Osorio, J., \& Wykowska, A. (2020). Adopting the intentional stance toward natural and artificial agents. Philosophical Psychology, 33(3), 369-395. https://doi.org/10.1080/09515089.2019.1688778

Putnam, V., \& Conati, C. (2019). Exploring the Need for Explainable Artificial Intelligence (XAI) in Intelligent Tutoring Systems (ITS). Los Angeles, 7.

Sahaï, A., Desantis, A., Grynszpan, O., Pacherie, E., \& Berberian, B. (2019). Action corepresentation and the sense of agency during a joint Simon task: Comparing human 
and machine co-agents. Consciousness and Cognition, 67, 44-55. https://doi.org/10.1016/j.concog.2018.11.008

Sahai, A., Pacherie, E., Grynszpan, O., \& Berberian, B. (2017). Co-representation of humangenerated actions vs. machine-generated actions: Impact on our sense of we-agency? 2017 26th IEEE International Symposium on Robot and Human Interactive Communication (RO-MAN), 341-345. https://doi.org/10.1109/ROMAN.2017.8172324

Samson, D., Apperly, I. A., Braithwaite, J. J., Andrews, B. J., \& Bodley Scott, S. E. (2010). Seeing it their way: Evidence for rapid and involuntary computation of what other people see. Journal of Experimental Psychology: Human Perception and Performance, 36(5), 1255-1266. https://doi.org/10.1037/a0018729

San Martín, R. (2012). Event-related potential studies of outcome processing and feedbackguided learning. Frontiers in Human Neuroscience, 6. https://doi.org/10.3389/fnhum.2012.00304

Santoni de Sio, F., \& van den Hoven, J. (2018). Meaningful Human Control over Autonomous Systems: A Philosophical Account. Frontiers in Robotics and AI, 5. https://doi.org/10.3389/frobt.2018.00015

Sarter, N. B., \& Woods, D. D. (1995). How in the World Did We Ever Get into That Mode? Mode Error and Awareness in Supervisory Control. Human Factors: The Journal of the Human Factors and Ergonomics Society, 37(1), 5-19. https://doi.org/10.1518/001872095779049516

Sarter, N. B., Woods, D. D., \& Billings, C. E. (1997). Automation surprises. Handbook of human factors and ergonomics, 2, 1926-1943. 
Sato, A., \& Yasuda, A. (2005). Illusion of sense of self-agency: Discrepancy between the predicted and actual sensory consequences of actions modulates the sense of selfagency, but not the sense of self-ownership. Cognition, 94(3), 241-255. https://doi.org/10.1016/j.cognition.2004.04.003

Sebanz, N., Bekkering, H., \& Knoblich, G. (2006). Joint action: Bodies and minds moving together. Trends in Cognitive Sciences, 10(2), 70-76. https://doi.org/10.1016/j.tics.2005.12.009

Sebanz, N., Knoblich, G., \& Prinz, W. (2003). Representing others' actions: Just like one's own? Cognition, 88(3), B11-B21. https://doi.org/10.1016/S0010-0277(03)00043-X

Sebanz, N., Knoblich, G., \& Prinz, W. (2005). How Two Share a Task: Corepresenting Stimulus-Response Mappings. Journal of Experimental Psychology: Human Perception and Performance, 31(6), 1234-1246. https://doi.org/10.1037/00961523.31.6.1234

Shekhar, S. S. (2019). Artificial intelligence in automation. Artificial Intelligence, 3085(06), $14-17$.

Sheridan, T. B., (2002). Humans and automation: System design and research issues (pp. xii, 264). Human Factors and Ergonomics Society.

Sheridan, T. B., \& Verplank, W. L. (1978). Human and Computer Control of Undersea Teleoperators: Defense Technical Information Center. https://doi.org/10.21236/ADA057655

Shneiderman, B., \& Plaisant, C. (2010). Designing the user interface: Strategies for effective human-computer interaction. Pearson Education India. 
Sidarus, N., Chambon, V., \& Haggard, P. (2013). Priming of actions increases sense of control over unexpected outcomes. Consciousness and Cognition, 22(4), 1403-1411. https://doi.org/10.1016/j.concog.2013.09.008

Sidarus, N., \& Haggard, P. (2016). Difficult action decisions reduce the sense of agency: A study using the Eriksen flanker task. Acta Psychologica, 166, 1-11. https://doi.org/10.1016/j.actpsy.2016.03.003

Sidarus, N., Vuorre, M., Metcalfe, J., \& Haggard, P. (2017). Investigating the Prospective Sense of Agency: Effects of Processing Fluency, Stimulus Ambiguity, and Response Conflict. Frontiers in Psychology, 8. https://doi.org/10.3389/fpsyg.2017.00545

Silver, C. A., Tatler, B. W., Chakravarthi, R., \& Timmermans, B. (2020). Social Agency as a continuum. Psychonomic Bulletin \& Review. https://doi.org/10.3758/s13423-020$01845-1$

Slater, M., Pérez Marcos, D., Ehrsson, H., \& Sanchez-Vives, M. V. (2009). Inducing illusory ownership of a virtual body. Frontiers in Neuroscience, 3. https://doi.org/10.3389/neuro.01.029.2009

Tanimoto, T., Shinohara, K., \& Yoshinada, H. (2017). Research on effective teleoperation of construction machinery fusing manual and automatic operation. ROBOMECH Journal, 4(1), 14. https://doi.org/10.1186/s40648-017-0083-5

Thellman, S., Silvervarg, A., \& Ziemke, T. (2017). Folk-Psychological Interpretation of Human vs. Humanoid Robot Behavior: Exploring the Intentional Stance toward Robots. Frontiers in Psychology, 8. https://doi.org/10.3389/fpsyg.2017.01962 
Timm, J., SanMiguel, I., Keil, J., Schröger, E., \& Schönwiesner, M. (2014). Motor Intention Determines Sensory Attenuation of Brain Responses to Self-initiated Sounds. Journal of Cognitive Neuroscience, 26(7), 1481-1489. https://doi.org/10.1162/jocn_a_00552

Tintarev, N., \& Masthoff, J. (2010). Designing and evaluating explanations for recommender systems. Recommender Systems Handbook, 479-510. https://doi.org/10.1007/978-0$387-85820-3$

Tintarev, N., \& Masthoff, J. (2012). Evaluating the effectiveness of explanations for recommender systems: Methodological issues and empirical studies on the impact of personalization. User Modeling and User-Adapted Interaction, 22(4-5), 399-439. https://doi.org/10.1007/s11257-011-9117-5

Ueda, S., Nakashima, R., \& Kumada, T. (2021). Influence of levels of automation on the sense of agency during continuous action. Scientific Reports, 14.

van der Wel, R. P. (2015). Me and we: Metacognition and performance evaluation of joint actions. Cognition, 140, 49-59. https://doi.org/10.1016/j.cognition.2015.03.011

van der Wel, R. P., Sebanz, N., \& Knoblich, G. (2012). The sense of agency during skill learning in individuals and dyads. Consciousness and Cognition, 21(3), 1267-1279. https://doi.org/10.1016/j.concog.2012.04.001

van Hateren, J. H. (2015). The origin of agency, consciousness, and free will. Phenomenology and the Cognitive Sciences, 14(4), 979-1000. https://doi.org/10.1007/s11097-0149396-5

Van Lent, M., Fisher, W., \& Mancuso, M. (2004, July). An explainable artificial intelligence system for small-unit tactical behavior. In Proceedings of the national conference on 
artificial intelligence (pp. 900-907). Menlo Park, CA; Cambridge, MA; London; AAAI Press; MIT Press; 1999.

Vantrepotte, Q., Berberian, B., Pagliari, M., \& Chambon, V. (2021). Leveraging human agency to improve confidence and acceptability in human-machine interactions. PsyArXiv. https://doi.org/10.31234/osf.io/6pvnh

Victor, T. W., Tivesten, E., Gustavsson, P., Johansson, J., Sangberg, F., \& Ljung Aust, M. (2018). Automation Expectation Mismatch: Incorrect Prediction Despite Eyes on Threat and Hands on Wheel. Human Factors, 60(8), 1095-1116. https://doi.org/10.1177/0018720818788164

Vinding, M. C., Pedersen, M. N., \& Overgaard, M. (2013). Unravelling intention: Distal intentions increase the subjective sense of agency. Consciousness and Cognition, 22(3), 810-815. https://doi.org/10.1016/j.concog.2013.05.003

Voss, M., Moore, J., Hauser, M., Gallinat, J., Heinz, A., \& Haggard, P. (2010). Altered awareness of action in schizophrenia: A specific deficit in predicting action consequences. Brain, 133(10), 3104-3112. https://doi.org/10.1093/brain/awq152

Wahn, B., Kingstone, A., \& König, P. (2018). Group benefits in joint perceptual tasks-a review: Group benefits in joint perceptual tasks. Annals of the New York Academy of Sciences, 1426(1), 166-178. https://doi.org/10.1111/nyas.13843

Wang, Z., Zheng, R., Kaizuka, T., \& Nakano, K. (2019). Relationship Between Gaze Behavior and Steering Performance for Driver-Automation Shared Control: A Driving Simulator Study. IEEE Transactions on Intelligent Vehicles, 4(1), 154-166. https://doi.org/10.1109/TIV.2018.2886654 
Wegner, D. M., Sparrow, B., \& Winerman, L. (2004). Vicarious Agency: Experiencing Control Over the Movements of Others. Journal of Personality and Social Psychology, 86(6), 838-848. https://doi.org/10.1037/0022-3514.86.6.838

Wegner, D. M., \& Wheatley, T. (1999). Apparent Mental Causation. American Psychologist, 13.

Wen, W. (2019). Does delay in feedback diminish sense of agency? A review. Consciousness and Cognition, 73, 102759. https://doi.org/10.1016/j.concog.2019.05.007

Wen, W., \& Haggard, P. (2018). Control Changes the Way We Look at the World. Journal of Cognitive Neuroscience, 30(4), 603-619. https://doi.org/10.1162/jocn_a_01226

Wen, W., Kuroki, Y., \& Asama, H. (2019). The Sense of Agency in Driving Automation. Frontiers in Psychology, 10, 2691. https://doi.org/10.3389/fpsyg.2019.02691

Wen, W., Yamashita, A., \& Asama, H. (2015a). The Sense of Agency during Continuous Action: Performance Is More Important than Action-Feedback Association. PLOS ONE, 10(4), e0125226. https://doi.org/10.1371/journal.pone.0125226

Wen, W., Yamashita, A., \& Asama, H. (2015b). The influence of action-outcome delay and arousal on sense of agency and the intentional binding effect. Consciousness and Cognition, 36, 87-95. https://doi.org/10.1016/j.concog.2015.06.004

Wen, W., Yamashita, A., \& Asama, H. (2015c). The influence of goals on sense of control. $\begin{array}{llll}\text { Consciousness } \quad \text { Cognition, } & \text { 83-90. }\end{array}$ https://doi.org/10.1016/j.concog.2015.08.012

Wen, W., Yun, S., Yamashita, A., Northcutt, B. D., \& Asama, H. (2021). Deceleration Assistance Mitigated the Trade-off Between Sense of Agency and Driving 
Performance. Frontiers in Psychology, $\quad$ 12, 643516. https://doi.org/10.3389/fpsyg.2021.643516

Wenke, D., Fleming, S. M., \& Haggard, P. (2010). Subliminal priming of actions influences sense of control over effects of action. Cognition, 115(1), 26-38. https://doi.org/10.1016/j.cognition.2009.10.016

Woods, D. D., \& Tinapple, D. (1999). Watching human factors watch people at work. Presidential Address, Presented at the 43rd Annual Meeting of the Human Factors and Ergonomics Society, Houston, TX. Multimedia Production Available at Http://Csel. Eng. Ohiostate. Edu/Hf99/. Announcement Deadlines: 1st Day of the Month Prior to the Desired Issue.

Wykowska, A., Chellali, R., Al-Amin, Md. M., \& Müller, H. J. (2014). Implications of Robot Actions for Human Perception. How Do We Represent Actions of the Observed Robots? International Journal of Social Robotics, 6(3), 357-366. https://doi.org/10.1007/s12369-014-0239-x

Yun, S., Wen, W., An, Q., Hamasaki, S., Yamakawa, H., Tamura, Y., Yamashita, A., \& Asama, H. (2018). Investigating the Relationship Between Assisted Driver's SoA and EEG. In L. Masia, S. Micera, M. Akay, \& J. L. Pons (Eds.), Converging Clinical and Engineering Research on Neurorehabilitation III (pp. 1039-1043). Springer International Publishing. https://doi.org/10.1007/978-3-030-01845-0_208

Zanatto, D., Chattington, M., \& Noyes, J. (2021). Sense of Agency in Human-Machine Interaction. In H. Ayaz, U. Asgher, \& L. Paletta (Eds.), Advances in Neuroergonomics and Cognitive Engineering (pp. 353-360). Springer International Publishing. https://doi.org/10.1007/978-3-030-80285-1_41 